\title{
Pathogenesis of an Experimental Model of Goodpasture's Hemorrhagic Pneumonitis
}

Thais H. Queluz, Irene Pawlowski, Michael J. Brunda, Jan R. Brentjens, Adrian O. Vladutiu, and Giuseppe Andres Departments of Microbiology, Pathology, and Medicine, State University of New York at Buffalo, Buffalo, New York 14214; the Renal and Immunopathology Laboratories of the Buffalo General Hospital, Buffalo, New York 14203; and the Department of Oncology and Virology, Roche Research Center, Hoffman-La Roche Inc., Nutley, New Jersey 07110

\begin{abstract}
The mechanisms that allow circulating basement membrane antibodies (Ab) to interact with the alveolar basement membrane (ABM) inducing Goodpasture's hemorrhagic pneumonitis are unknown. In laboratory animals the $A B M$ is inaccessible to phlogogenic amounts of $\mathrm{ABM} A \mathrm{Ab}$ unless the permeability of the unfenestrated alveolar endothelium is increased. This study was designed to test the hypothesis that in the mouse polypeptide mediators, generated by activated lymphoid cells or cells infected by viruses, contribute to the pathogenesis of passive Goodpasture's hemorrhagic pneumonitis. In naive mice that received rabbit $\mathrm{ABM} \mathrm{Ab}$, these bound to the glomerular basement membrane but not to the $A B M$ and their lungs were normal. In the lungs of mice injected with human recombinant IL-2 and IFN- $\alpha$ specific binding of ABM IgG, $\mathrm{C3}$, and fibrinogen to the $\mathrm{ABM}$, diffuse and severe erythrocyte extravasation, and accumulation of mononuclear and polymorphonuclear leukocytes were constantly observed. ABM Ab and IL-2 or ABM Ab and IFN- $\alpha$ did not produce comparable effects. Mice injected only with IL-2 and IFN- $\alpha$ had enlarged, edematous lungs without pulmonary hemorrhages. The results show that the synergism of IL-2 and IFN- $\alpha$ convert the lung into a preferential target for AMB Ab, suggesting that cytokines may have a role in the pathogenesis of human Goodpasture's pneumonitis. (J. Clin. Invest. 1990. 85:1507-1515.) Goodpasture's pneumonitis - basement membrane antibodies • cytokines
\end{abstract}

\section{Introduction}

Goodpasture's disease is characterized by the association of severe glomerulonephritis and hemorrhagic pneumonitis induced by autoantibodies reactive with antigens of the basement membranes (1). Although the pathogenesis of the glomerulonephritis is well established, some crucial aspects of hemorrhagic pneumonitis remain unknown. There is no clear-cut relationship between the levels of circulating antibasement membrane antibodies and episodes of pulmonary hemorrhage (1-3), which are only occasionally associated with a rise in anti-basement membrane antibody titer but are often related to the onset of intercurrent infections, suggesting that additional factors contribute to pulmonary injury $(2,3)$.

Address correspondence to Dr. Giuseppe Andres, Massachusetts General Hospital-East, Harvard Medical School, Pathology Research, Charlestown Naval Yard, 149 13th Street, Charlestown, MA 02129.

Received for publication 28 June 1989 and in revised form 7 December 1989.

J. Clin. Invest.

(c) The American Society for Clinical Investigation, Inc.

0021-9738/90/05/1507/09 \$2.00

Volume 85, May 1990, 1507-1515
Experimentally, only glomerulonephritis can be induced in sheep by active (4) or passive (5) immunization with basement membrane preparations. Monkeys injected with human antibasement membrane antibodies develop glomerulonephritis but not hemorrhagic pneumonitis (6). In rodents anti-basement membrane antibodies readily bind to the glomerular basement membrane (GBM) ${ }^{1}$ but not to the alveolar basement membrane (ABM) (7-10). The preferential binding of antibasement membrane antibodies to the GBM is attributed to the largely fenestrated glomerular endothelium which contrasts with the unfenestrated alveolar endothelium, acting as a barrier preventing or restraining the access of circulating antibodies to the ABM. Previous studies have shown that rodents injected with nephritogenic doses of anti-basement membrane IgG did not develop pulmonary hemorrhage unless the permeability of the alveolar endothelium was increased by prolonged exposure to high concentrations of inspired oxygen $(7,8)$ or by tracheal instillation of gasoline (9). Administration of oxygen or of gasoline, however, are artificial procedures, unlikely counterparts of an autoimmune response.

The present study was designed to test the hypothesis that an inflammatory antigen-antibody reaction at the level of the ABM requires an increased permeability of the alveolar endothelium by mediators generated by activated lymphoid cells and cells infected with viruses. The results show that IL-2 and IFN- $\alpha$ exert a critical role in the pathogenesis of an experimental model of passive Goodpasture's hemorrhagic pneumonitis.

\section{Methods}

Mice

Female mice, 6-10 wk old, of the following strains were used: C57BL/6 (Charles River Breeding Laboratories, Inc., Wilmington, MA); and beige C57BL/6J-bg' and C57BL/6J (Jackson Laboratory, Bar Harbor, ME). The mice were allowed free access to mouse pellets (Teklad, Winfield, CT) and water.

\section{Experimental design}

Groups of 10 mice were used in separate experiments. The mice were killed on day 4 of the experiments, $2 \mathrm{~h}$ after the last injection of cytokines. Blood was collected from the right axillary artery under ether anesthesia. Lungs and kidneys were removed and processed for radioisotope, immunofluorescence (IF), and light and electron microscopy techniques. The designs of the experiments are summarized in Table I.

Groups I $a$ and Ib. C57BL/6 mice received for two consecutive days one intraperitoneal injection of $5 \mathrm{mg}$ rabbit (Rb) ABM IgG. Groups Ia and $\mathrm{Ib}$ included mice that received two different preparations of ${ }^{125} \mathrm{I}$ RbABM IgG, respectively (preparations 1 and 2).

1. Abbreviations used in this paper: ABM, alveolar basement membrane; GBM, glomerular basement membrane; IF, immunofluorescence; K, kidney; L, lungs; NRb, normal rabbit; $R b$, rabbit. 
Table I. Experimental Design

\begin{tabular}{lllllll}
\hline Group & \multicolumn{1}{c}{ Strain } & IL-2 & IFN- $\alpha$ & $\begin{array}{c}\text { RbABM } \\
\text { IgG }\end{array}$ & $\begin{array}{c}\text { NRb } \\
\text { IgG }\end{array}$ & $\begin{array}{c}\text { I25I-RbABM } \\
\text { IgG }\end{array}$ \\
\hline Ia & C57BL/6 & - & - & + & - & Prep 1 \\
Ib & C57BL/6 & - & - & + & - & - \\
IgG
\end{tabular}

For details, see text. $* 50,000 \mathrm{U} /$ injection instead of $100,000 \mathrm{U} /$ injection administered to mice in other groups. Prep, preparation.

Group II. C57BL/6 mice received intraperitoneal injections of 100,000 U IL-2 and 100,000 U IFN- $\alpha$, twice the first day, three times daily for the subsequent $2 \mathrm{~d}$, and once the fourth day before killing (total of nine injections) (11).

Groups IIIa, IIIb, IIIc, and IIId. C57BL/6 mice were injected with IL-2, IFN- $\alpha$, and RbABM IgG. The schedule of cytokine injection was as in group II. RbABM IgG was given in two fractionated doses of $5 \mathrm{mg}$ each on days 2 and 3 to assure persistence of antibodies in the circulation during the entire period of cytokine administration. Group IIIa included mice injected with 100,000 U IL-2 and IFN- $\alpha$ per injection and a total of $10 \mathrm{mg}$ RbABM IgG. Group IIIb included mice injected with $50,000 \mathrm{U}$ IL-2 and IFN- $\alpha$ per injection, and a total of $10 \mathrm{mg}$ of RbABM IgG. Groups IIIc and IIId included mice used for paired label radioisotope studies (see below). They received 100,000 U IL-2 and IFN- $\alpha, 10 \mathrm{mg}$ RbABM IgG, and $10 \mathrm{mg}$ normal rabbit (NRb) IgG (group IIIc). The results obtained in group IIIc were compared with those obtained in another group of mice (group IIId) injected with 10 $\mathrm{mg}$ RbABM IgG and $10 \mathrm{mg}$ NRb IgG only.

Group IV. C57BL/6 mice were injected with $100,000 \mathrm{U}$ IL-2 with the same schedule used for group II, and with $10 \mathrm{mg} \mathrm{RbABM} \mathrm{IgG.}$

Group $V$. C57BL/6 mice were injected with $100,000 \mathrm{U}$ IFN- $\alpha$, with the same schedule used in group II, and $10 \mathrm{mg}$ of RbABM IgG.

Groups VIa and VIb. These groups included beige C57BL/6J-bg' mice deficient in NK cells (12-14) (group VIa), and NK cell normal C57BL/6J mice that served as control (group VIb). Both groups were injected with 50,000 U of IL-2 and IFN- $\alpha$ following the schedule used in group II, and with $10 \mathrm{mg} \mathrm{RbABM} \mathrm{IgG.}$

Groups VIIa and VIIb. These groups included beige C57BL/6J-bg mice injected with 100,000 U IL-2 following the schedule used in mice in group II, and $10 \mathrm{mg}$ RbABM IgG (group VIIa). As control, normal C57BL/6J mice were similarly injected with IL-2 and RbABM IgG (group VIIb).

\section{Preparation of rabbit anti-rat $A B M$ serum}

Rat ABM was prepared according to a modification (7) of a method described by Meezan et al. (15). The yield of lyophilized ABM was 730 mg per 120 pairs of lungs (Pel-Freeze Biologicals, Rogers, AR). New Zealand White rabbits (Rb) (Beckens Farms, Sanburn, NY) were immunized intradermally three times, at 2-wk intervals, with $2 \mathrm{mg} \mathrm{ABM}$ in complete Freund's adjuvant (Difco Laboratories Inc., Detroit, MI).
When the titer of the antisera, measured by indirect IF microscopy, was $>1: 2,000$, the rabbits were bled and reimmunized. Bleedings and booster injections were repeated every other week for four times, and the animals were then killed. Pooled sera were heat inactivated $\left(56^{\circ} \mathrm{C}\right.$ for $30 \mathrm{~min}$ ) and stored at $-20^{\circ} \mathrm{C}$ in $10-\mathrm{ml}$ aliquots. Gamma globulin fractions of immune sera and of sera obtained from normal rabbits were isolated by precipitation with $4 \mathrm{~mol}$ ammonium sulfate. IgG fractions were prepared by filtration on a column of protein A agarose (Sigma Chemical Co., St. Louis, MO). The same pools of immune or nonimmune IgG were used throughout the study. The titer of RbABM IgG was $1: 5,120$ and 1:2,560 when tested, respectively, on sections of normal mouse lung and kidney.

\section{Cytokines}

Highly purified human recombinant IL-2 (Cetus Corp., Emeryville, CA), produced from Escherichia coli had a sp act of $3 \times 10^{6}$ Cetus units/mg protein. The biochemical and immunologic properties of the preparation have been described previously (16). Human recombinant IFN- $\alpha$ (Hoffmann-La Roche Inc., Nutley, NJ), active in murine cells, had a sp act of $7.9 \times 10^{7} \mathrm{U} / \mathrm{mg}$ protein, and its biochemical and immunologic properties have been previously described $(17,18)$. Both cytokines were diluted in distilled water containing $0.2 \%$ BSA (INC Immuno-Biologicals, Lisle, IL).

\section{IF microscopy}

FITC-conjugated IgG anti-rabbit IgG and anti-mouse C3 (Cappel Laboratories, Cochranville, PA), anti-mouse fibrinogen, and albumin (Nordic Immunological Laboratories, Capistrano Beach, CA) were monospecific when tested by immunoelectrophoresis and immunodiffusion. For direct IF, sections of mouse lung and kidney tissues obtained at death were processed as described in a previous publication (19). Indirect IF was performed by incubating sections of normal mouse or rat kidney and lung with RbABM IgG as a primary antibody, and FITC-conjugated goat anti-rabbit IgG as a secondary antibody. Stained sections were examined with an Ortholux microscope (E. Leitz, Inc., Rockleigh, NJ) equipped with an HBO-200 high-pressure mercury vapor lamp and appropriate exciting and barrier filters. The amount and extent of the immune deposits were semiquantitatively graded on a scale from 0 to $3(0$, absent; 1 , minimal; 2 , moderate; 3 , marked and extensive). 


\section{Morphologic light and electron microscopy studies}

Fragments of lung and kidney tissue were fixed in $10 \%$ buffered formalin and embedded in paraffin. 3- $\mu$ m-thick sections, stained with hematoxilin-eosin or periodic acid-Schiff, were studied by light microscopy. Additional light microscopy studies were performed using $1-\mu \mathrm{m}$-thick sections of tissue, processed for electron microscopy as described below, and stained with toluidine blue. The extent and severity of lesions was semiquantitatively evaluated on a scale from 0 to 3 (20). Tissue for electron microscopy was fixed with the Karnovsky's paraformaldehyde-glutaraldehyde solution (21), postfixed with $1 \%$ osmium tetroxide, and embedded in Epon 812-Araldite. Thin sections stained with uranyl acetate and lead citrate were studied with a JEOL 100 S electron microscope.

\section{Studies with radiolabeled $R b A B M$ IgG and NRb IgG}

Immune and nonimmune $\mathrm{Rb}$ IgG were radioiodinated using the chloramine-T method (22). The specific activities of the two preparations of ${ }^{125} \mathrm{I}-\mathrm{RbABM}$ IgG used in the study were 0.87 and $0.35 \mu \mathrm{Ci} / \mu \mathrm{g}$, respectively. The sp act of ${ }^{131} \mathrm{I}-\mathrm{NRb} \mathrm{IgG}$ was $1.07 \mu \mathrm{Ci} / \mu \mathrm{g}$. Radiolabeled IgG was mixed with $5 \mathrm{mg}$ of unlabeled RbABM IgG or NRb IgG and given intraperitoneally on days 2 and 3 of the experiments. Harvested lungs and kidneys were weighed, thoroughly rinsed, and counted in an LKB-Wallace 1282 compugamma counter (LKB Diagnostics, Inc., Gaithersburg, MD). The radioactivity of $0.5 \mathrm{ml}$ mouse blood and of the injected preparations was also measured.

Experiments performed with ${ }^{125} I-R b A B M I g G$. Mice in groups IIIa, VIa and VIb, and VIla and VIIb were injected with $\sim 1 \times 10^{6} \mathrm{cpm}$ ${ }^{125} \mathrm{I}-\mathrm{RbABM}$ IgG and the results were compared with those obtained in mice of group Ia injected with the same radiolabeled preparation. Mice in groups IIIb, IV, and V were injected with $2.5 \times 10^{7} \mathrm{cpm}{ }^{125} \mathrm{I}$ RbABM IgG and the results were compared with those obtained in mice of group Ib injected with the same radiolabeled preparation. The results were calculated as counts/minute per $0.2 \mathrm{~g}$ of tissue. When groups Ia, IIIa, and IIIb were compared, the results were expressed in terms of radioisotope disintegration per $0.2 \mathrm{~g}$ of tissue.

Paired label radioisotope studies (23). Mice in groups IIIc and IIId were simultaneously injected with $1 \times 10^{6} \mathrm{cpm}^{125} \mathrm{I}-\mathrm{RbABM} \mathrm{IgG}$ and 1 $\times 10^{6} \mathrm{cpm}^{131} \mathrm{I}-\mathrm{NRb}$ IgG mixed with $5 \mathrm{mg}$ unlabeled RbABM IgG and $5 \mathrm{mg} \mathrm{NRb}$ IgG. The specific binding of RbABM IgG to the lungs (L) or kidneys (K) was calculated using the following formula (24):

${ }^{125} \mathrm{I}(\mathrm{L})$ or $(\mathrm{K})={ }^{125} \mathrm{I}(\mathrm{L})$ or $(\mathrm{K})-\frac{\left[{ }^{131} \mathrm{I}(\mathrm{L}) \text { or }(\mathrm{K}) \times{ }^{125} \mathrm{I} \text { blood }\right]}{\left[{ }^{131} \mathrm{I} \text { blood }\right]}$.

\section{Statistical analysis}

The nonparametric Mann-Whitney $U$ test for paired samples was used $(25)$ and the results were given as mean \pm SEM. $P$ values $<0.05$ were considered significant.

\section{Results}

When tested by indirect IF, RbABM IgG reacted with the basement membranes in lungs and kidneys of rats and mice. Rats injected intravenously for two consecutive days with 5 $\mathrm{mg}$ of RbABM IgG developed proteinuria and glomerular lesions during the autologous phase. Linear deposits of Rb IgG were present in the GBM but not in the ABM (data not shown).

Groups Ia and Ib: mice injected with RbABM IgG only. Macroscopically the lungs and the kidneys appeared normal. The wet weight of the lungs was normal (Table II). RbABM IgG was bound more to the kidneys than to the lungs (groups Ia and Ib, Fig. 1). By IF technique deposits of Rb IgG were undetectable in the ABM (Fig. 2) but prominent in the GBM (Fig. 3). By light microscopy examination (Table II) the lungs were normal, and only a few polymorphonuclear leukocytes
Table II. Weights and Morphologic Findings in Lungs of Mice

\begin{tabular}{lcccc}
\hline Group & Weight & Edema & Hemorrhages & $\begin{array}{c}\text { Inflammatory } \\
\text { cells }\end{array}$ \\
\hline Ia & $g$ & & & \\
II & $0.11 \pm 0$ & 0 & 0 & $0.4 \pm 0.1$ \\
IIIa & $0.20 \pm 0^{*}$ & $1.6 \pm 0.3^{*}$ & $0.3 \pm 0.3$ & $1.3 \pm 0.1^{*}$ \\
IIIb & $0.21 \pm 0^{*}$ & $1.9 \pm 0.3^{*}$ & $1.5 \pm 0.2^{* \ddagger}$ & $0.9 \pm 0.1^{*}$ \\
IIIc & $0.22 \pm 0^{*}$ & $3 \pm 0^{*}$ & $1.6 \pm 0.2^{*}$ & $1.8 \pm 0.1^{*}$ \\
IIId & $0.11 \pm 0^{\S}$ & $1.5 \pm 0.1^{*}$ & $1.8 \pm 0.2^{* \ddagger}$ & $1.3 \pm 0.2^{*}$ \\
IV & $0.16 \pm 0^{*}$ & $0.6 \pm 0.2$ & $0.2 \pm 0.1$ & $1.2 \pm 0.1^{*}$ \\
V & $0.11 \pm 0$ & 0 & $0.2 \pm 0.1$ & $0.9 \pm 0.1$ \\
VIa & $0.13 \pm 0$ & $0.5 \pm 0.2$ & $0.1 \pm 0.1$ & $0.6 \pm 0.3$ \\
VIb & $0.25 \pm 0^{\prime \prime}$ & $3 \pm 0^{\prime \prime}$ & $3 \pm 0^{\prime \prime}$ & $1 \pm 0$ \\
VIIa & $0.18 \pm 0$ & $0.5 \pm 0.5$ & $0.3 \pm 0.2$ & $1.2 \pm 0.2$ \\
VIIb & $0.17 \pm 0$ & $1 \pm 0.2$ & $0.9 \pm 0.1^{1}$ & $2 \pm 0.2$ \\
\hline
\end{tabular}

${ }^{*} P<0.05$ compared with group Ia; ${ }^{\ddagger} P<0.05$ compared with group II; ${ }^{\S} P<0.01$ compared with group IIIc; $" P<0.05$ compared with group VIa; " $P<0.05$ compared with group VIIa.

were seen in some glomeruli. The study by electron microscopy confirmed the absence of pulmonary lesions, and with the exception of the presence of a small number of polymorphonuclear leukocytes, the renal glomeruli also appeared normal. These results indicated that, though not highly nephritogenic, the heterologous anti-rat ABM IgG used in the experiments was adequate to test the hypothesis proposed in this study.

Group II: mice injected with IL-2 and IFN- $\alpha$. The lungs were enlarged and edematous, and their wet weight was increased (Table II). The kidneys were pale. Large amounts of fluid were found in the abdominal and pleural cavities. Minimal and focal deposits of fibrinogen but not albumin were present in the alveolar septa. By light microscopy large, cir-

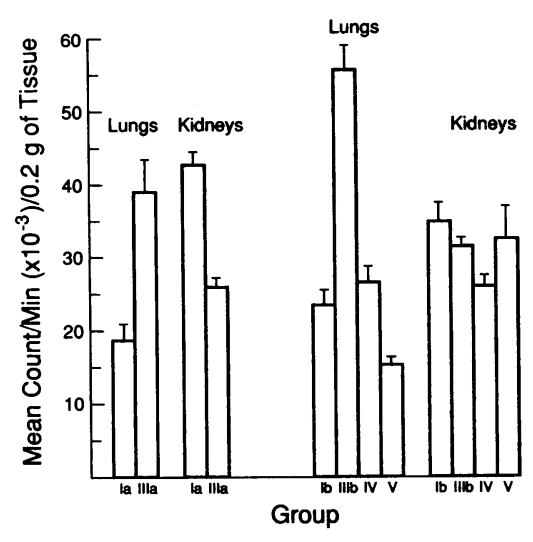

Figure 1. Results of two groups of experiments are shown on the left and on the right side of the figure. On the left, binding of $\mathrm{RbABM}$ IgG to the lungs and kidneys of mice injected with RbABM IgG only (group Ia), and mice injected with RbABM IgG, IL-2, and IFN- $\alpha$ (group IIIa). IL-2 and IFN- $\alpha$ increase the binding of Rb IgG to the lungs and decrease the binding to the kidneys. On the right it can be seen that IL-2 and IFN- $\alpha$, even in lower doses, exert the same effect (group IIIb) as compared with mice injected with RbABM IgG alone (group Ib). In contrast, IL-2 only (group IV) and IFN- $\alpha$ only (group V) do not increase binding of RbABM IgG to the lungs. 


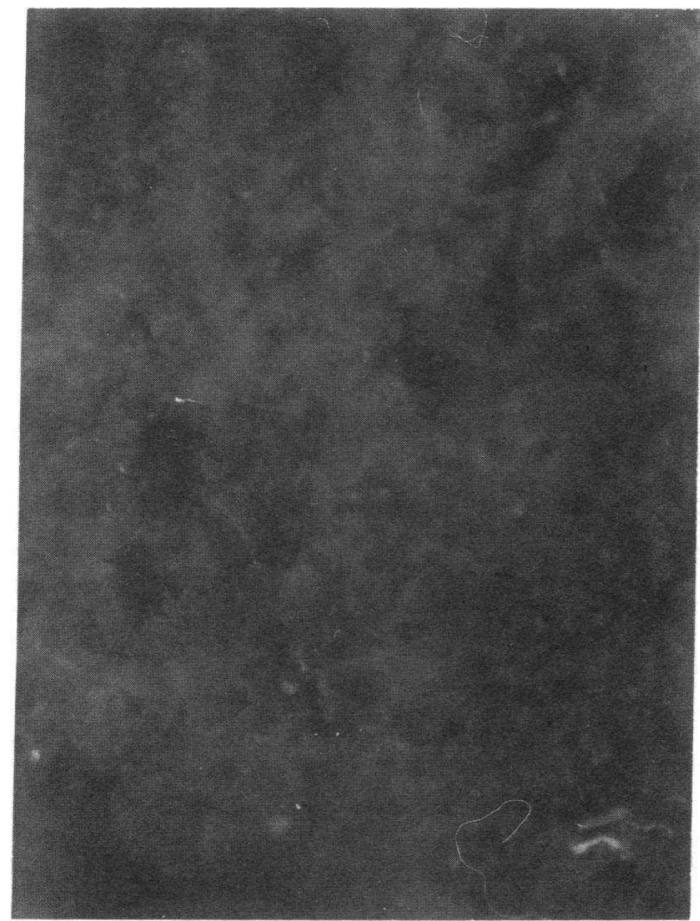

Figure 2. IF micrograph. Absence of immune deposits in the alveolar capillary walls of a mouse injected with RbABM IgG (group Ia). $\times \mathbf{4 0 0}$.

cumferential areas of fluid extravasation were seen around veins, venules, and some arteries (Table II) (Fig. 4). The endothelium of these vessels was swollen and vacuolated, and the alveolar septa contained an increased number of mononuclear leukocytes. By electron microscopy adhesion of lymphocytes

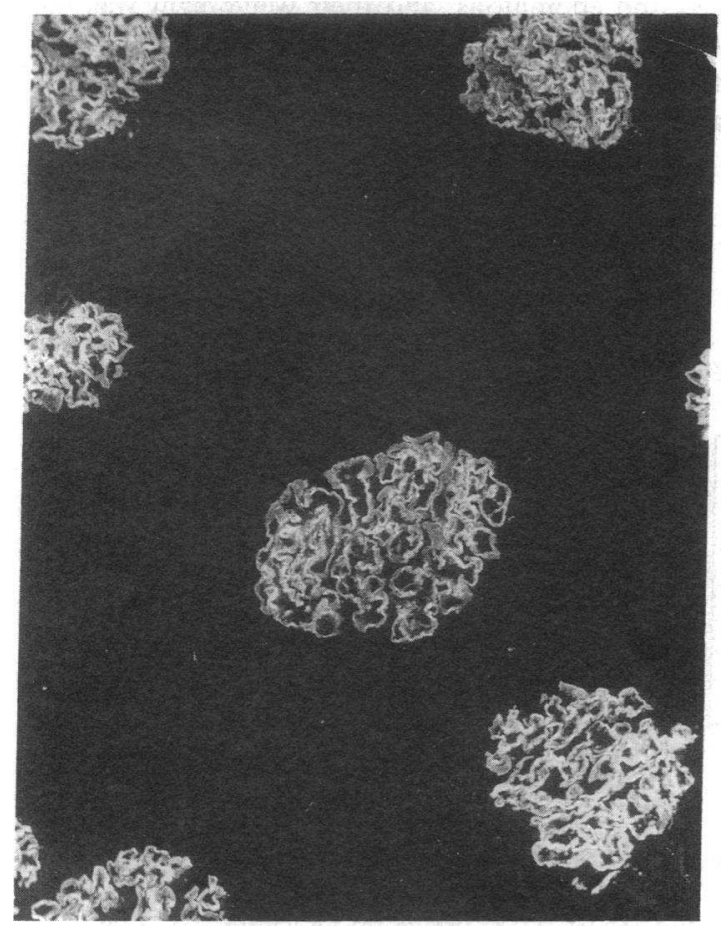

Figure 3. IF micrograph. Linear deposits of Rb IgG in the GBM of a mouse injected with $\mathrm{RbABM}$ IgG (group Ia). $\times \mathbf{4 0 0}$.

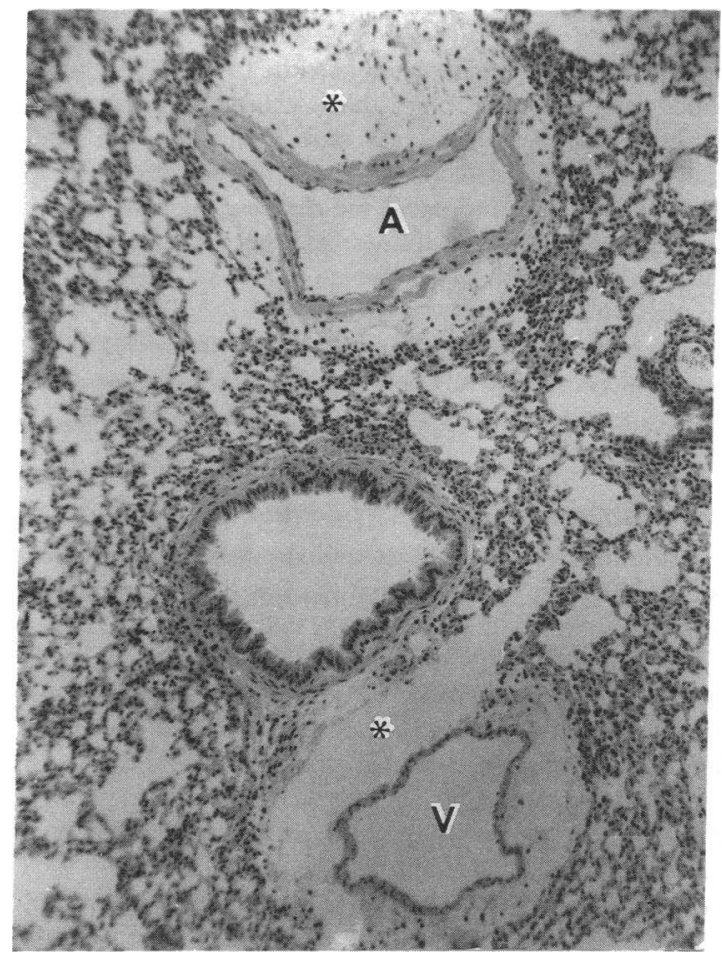

Figure 4. Light micrograph showing part of the lung of a mouse injected with IL-2 and IFN- $\alpha$ (group II). Edema (asterisks) around a vein $(V)$ and an artery $(A)$. Hemotoxylin and eosin. $\times 400$.

and polymorphonuclear leukocytes to the endothelium with detachment of the endothelium from the ABM (Fig. 5) and extravasation of fluid into the alveolar capillary walls and the alveolar space were observed.

Group III: mice injected with IL-2, IFN- $\alpha$, and $R b A B M$ $\operatorname{IgG}$. A group of mice received $100,000 \mathrm{U}$ of IL-2 and IFN- $\alpha$ (group IIIa), while another group received 50,000 U of IL-2 and IFN- $\alpha$ per injection (group IIIb) (Fig. 1). The findings in the two groups were comparable and therefore are described together.

The lungs were enlarged, edematous, and hemorrhagic. The wet weight was increased when compared with mice in group Ia (Table II). The kidneys were pale. Large amounts of hemorrhagic fluid were present in the abdominal and pleural cavities.

The study conducted in group IIIa with radiolabeled RbABM IgG showed that IL-2 and IFN- $\alpha$ reversed the lung/ kidney binding ratio of $\mathrm{RbABM} \mathrm{IgG}$, as compared with mice in groups Ia and Ib (Fig. 1). In contrast, fixation of RbABM IgG to the kidneys was significantly decreased as compared with mice in group Ia $(P=0.0005)$ (Fig. 1). In mice injected with 50,000 U IL-2 and IFN- $\alpha$ (group IIIb) the binding of RbABM IgG to the lung was not significantly lower than in mice injected with $100,000 \mathrm{U}$ (group IIIa) (Fig. 6).

Evidence that IL-2 and IFN- $\alpha$ induced a marked, preferential, and specific binding of RbABM IgG to the lungs was provided by studies performed with the paired label radioisotope technique (Fig. 7). IL-2 and IFN- $\alpha$ did not cause a statistically significant increase in binding of RbABM IgG to the kidneys compared with control. In contrast, IL-2 and IFN- $\alpha$ significantly increased the specific binding of RbABM IgG to the lungs $(P<0.00009)$. 


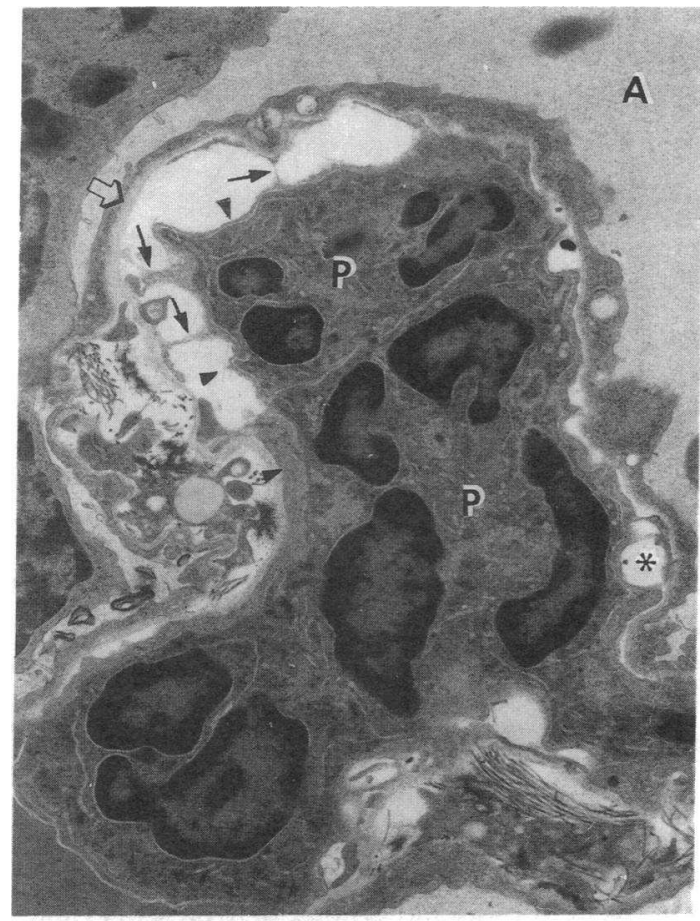

Figure 5. Electron micrograph: mouse of group II. Characteristic aspects of the interaction between the endothelium of an alveolar capillary wall and two polymorphonuclear leukocytes. A rim of endothelium (small arrowheads) is adherent to the surface of polymorphonuclear leukocytes $(P)$. A few thin stretches of endothelial cytoplasm (small arrows) maintain the contact with the endothelium still attached to the basal lamina, which, in some part, is devoid of endothelial cover (open arrow). Asterisk, An abnormal space resulting from the detachment of the endothelium from the basal lamina. $A$, Alveolar space. $\times 15,000$.

Marked, focal, and linear deposits of Rb IgG were consistently found in the ABM, usually adjacent or in proximity to veins and venules (Fig. 8). Similar, but less abundant, deposits of C3 (Fig. 9) and fibrinogen (Fig. 10) were present in the same areas. Deposits of albumin were absent. By light microscopy examination severe edema, hemorrhages, and marked exudative lesions (mainly polymorphonuclear leukocytes) were

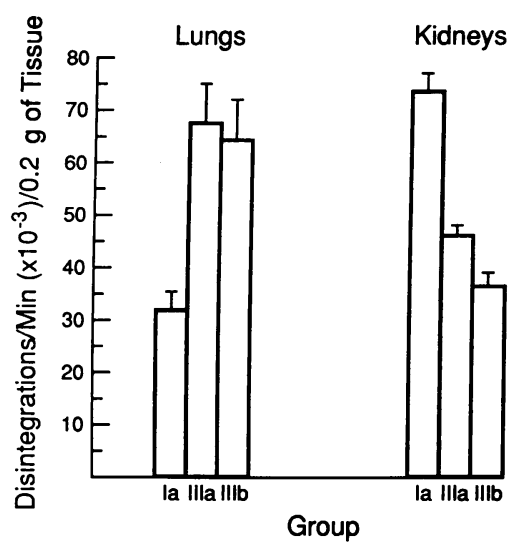

Figure 6. Binding of the RbABM IgG to the lungs and kidneys of groups of mice injected with RbABM IgG (group Ia); RbABM IgG, 100,000 U/injection of IL-2, and IFN- $\alpha$ (group IIIa); and RbABM IgG, 50,000 U/injection of IL-2, and IFN- $\alpha$ (group IIIb). It can be seen that injections of IL-2 and IFN- $\alpha$ increase the binding of RbABM IgG to the lungs. No difference, however, was observed between mice injected with 100,000 and $50,000 \mathrm{U}$ of cytokines.

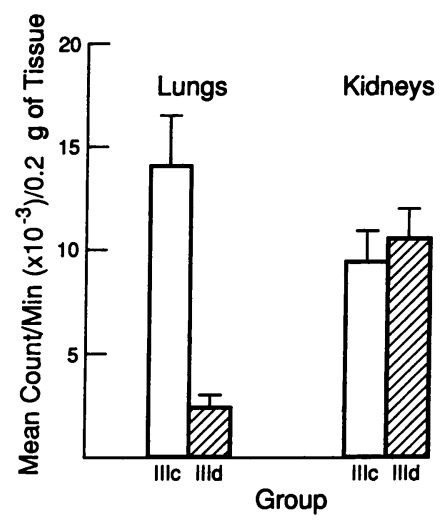

Figure 7. Results of an experiment performed with the paired label isotope technique. Injections of IL- 2 and IFN- $\alpha$ (open bars) significantly increased the specific binding of RbABM IgG to the lungs but not to the kidneys (group IIIc), as compared with controls (hatched bars) injected only with RbABM IgG and NRb IgG (group IIId).

found around and in proximity to veins and venules (Table II) (Fig. 11). By electron microscopy there was a marked increase in the number of polymorphonuclear leukocytes, as compared with mice in group II. A moderate increase in the number of polymorphonuclear leukocytes was also noted in renal glomeruli.

Group IV: mice injected with IL-2 and RbABM IgG. The lungs were edematous but not as enlarged as the lungs of mice in group III. The wet weight was slightly increased (Table II). Superficial hemorrhages were not present. Mild to moderate amounts of nonhemorrhagic fluid were found in the pleural and abdominal cavities. The macroscopic aspect of the kidneys was normal. Binding of RbABM IgG to the lungs was not significantly increased as compared with mice in group Ib, and was similar to the kidney binding (Fig. 1).

Only a few small deposits of $\mathrm{Rb}$ IgG were observed in the $\mathrm{ABM}$ by IF technique, whereas deposits of $\mathrm{C} 3$ and fibrinogen were minimal or absent. No difference was observed in glomerular deposits of Rb IgG as compared with other groups. The lesions detected by light microscopy were minimal perivenous edema and moderate perivascular infiltrates of mononuclear and polymorphonuclear cells, and accumulation of mononuclear cells in the alveolar septa. Hemorrhages were not observed (Table II). By electron microscopy the endothelium appeared normal and pathologic aspects of lymphocyte-endothelium interaction were not seen. The glomeruli appeared normal.

Group V: mice injected with IFN- $\alpha$ and RbABM IgG. Macroscopically the lungs and kidneys appeared normal. The wet weight of the lungs was normal (Table II). RbABM IgG was bound less to the lungs than to the kidneys. Further, binding to the lungs was less than that of group Ib (Fig. 1). Fixation of Rb IgG to the ABM was not detectable by IF technique, whereas it was unchanged in GBM as compared with other groups of mice. The morphology of lungs and kidneys was normal.

Groups VIa and VIb: beige C57BL/6J-bg ${ }^{J}$ and C57BL/6J mice injected with $I L-2, I F N-\alpha$, and $R b A B M I g G$. In these experiments tissue binding of RbABM IgG, immunohistologic and morphologic findings in beige C57BL/6J-bg (group VIa) and in control C57BL/6J (group VIb) were compared. The lungs of $\mathrm{C} 57 \mathrm{BL} / 6 \mathrm{~J}$ mice had lesions comparable to those of mice in group III. The wet weight of the lungs was increased (Table II) and the binding of RbABM IgG was higher than in group VIb (Fig. 12). Marked, focal, linear deposits of Rb IgG were present in the ABM (Fig. 13, inset). Edema, hemorrhages, and exudative lesions were severe (Table II). Deposits of 


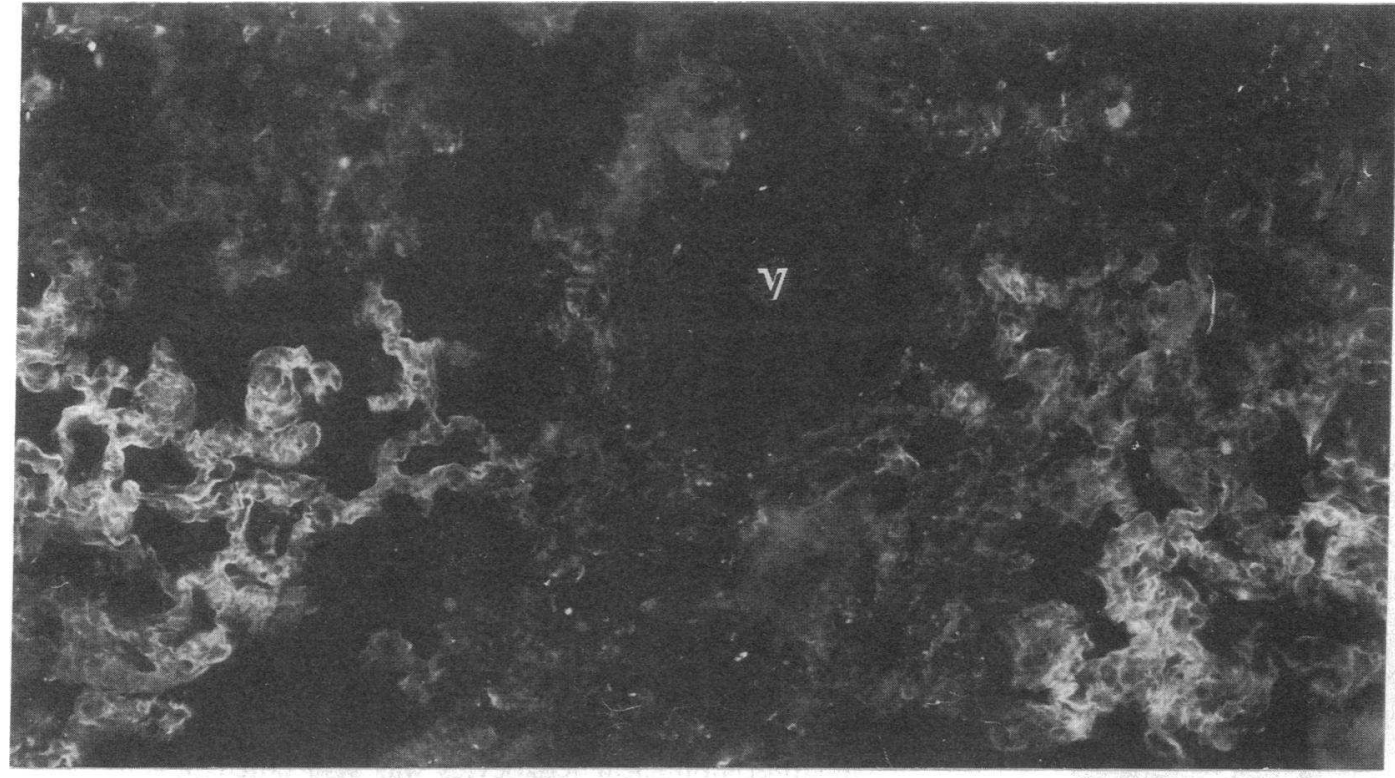

Figure 8. IF micrograph showing linear deposits of rabbit IgG in the ABM of a mouse injected with IL-2, IFN- $\alpha$, and RbABM IgG (group IIIa). The deposits have a focal distribution. $V$, The lumen of a vein. $\times 600$.
RbABM IgG in GBM and morphology of the kidneys were similar to those in mice of group III.

In beige C57BL/6J-bg ${ }^{\mathrm{J}}$ mice the pulmonary lesions were minimal or absent and the macroscopic aspect and wet weight of lungs were normal. Binding of RbABM IgG was lower than in group VIa (Fig. 12). Binding to the kidneys was similar in the groups VIa and VIb. Deposits of Rb IgG were not detectable by IF microscopy (Fig. 13). Perivenous edema and cellular infiltration were focal and minimal, and hemorrhages were absent (Table II). Aspects of pathologic endothelial-lymphocyte interactions were not observed by electron microscopy and only mild degenerative changes of endothelial and epithelial type I cells were seen. Deposits of Rb IgG in GBM and glomerular morphology were comparable to those in other groups of mice.

Groups VIIa and VIIb: beige C57BL/6J-bg ${ }^{J}$ and C57BL/ $6 J$ mice injected with $I L-2$ and $R b A B M I g G$. In these experiments tissue binding of RbABM IgG and immunohistologic and morphologic findings obtained in beige C57BL/6J-bg (group VIIa) and control C57BL/6J mice (group VIIb) were compared. The lungs of $\mathrm{C} 57 \mathrm{BL} / 6 \mathrm{~J}$ mice had lesions similar to those seen in mice in group IV. The wet weight was normal (Table II). Binding of RbABM IgG is shown in Fig. 12. A few faint deposits of IgG were detectable by IF microscopy.

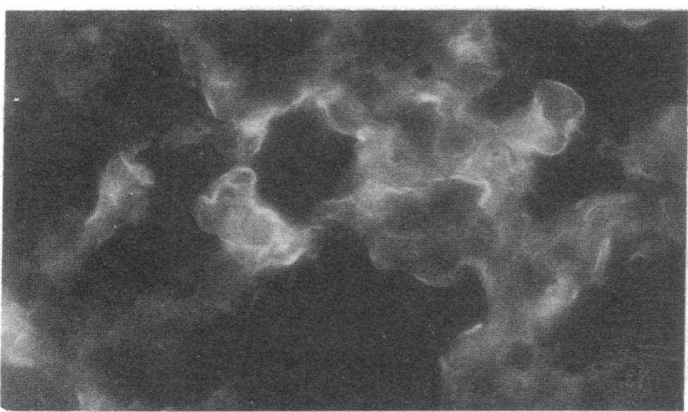

Figure 9. IF micrograph. Linear deposit of mouse $\mathrm{C} 3$ in the ABM of a mouse of group IIIb. $\times 800$.
Edema, hemorrhage, and especially infiltration of mononuclear cells in the walls of veins and venules were present (Table II). Electron microscopy findings were as in mice of group IV. The findings in the kidneys were also comparable to those in mice of group IV.

In beige $\mathrm{C} 57 \mathrm{BL} / 6 \mathrm{~J}-\mathrm{bg}^{\mathrm{J}}$ mice, macroscopically the lungs were normal and the pulmonary lesions were less severe than in mice of group VIIb. The wet weight was normal (Table II). Binding of RbABM IgG was lower than in group VIIb (Fig. 12). Immune deposits of $\mathrm{Rb}$ IgG were undetectable by IF microscopy. Edema and hemorrhages, but not perivascular infiltrates of inflammatory cells were less evident than in mice of group VIIb (Table II). Only minimal degenerative changes of endothelial and epithelial cells were seen by electron microscopy. The findings in the kidneys were not different from those in mice of groups VIIb and IV.

\section{Discussion}

The rationale for our experiments was based on the notion, confirmed by the present study, that phlogogenic amounts of anti-basement membrane IgG do not bind to the ABM unless the permeability of the unfenestrated alveolar endothelium is increased. We postulated that polypeptide mediators released

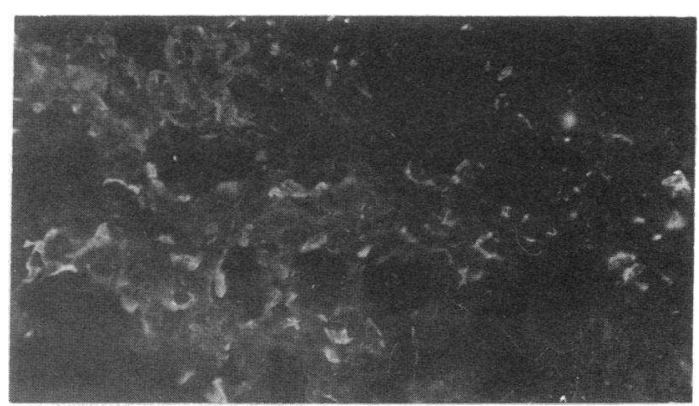

Figure 10. IF micrograph. Deposits of mouse fibrinogen in the alveolar capillary walls of a mouse of group IIIb. $\times 400$. 


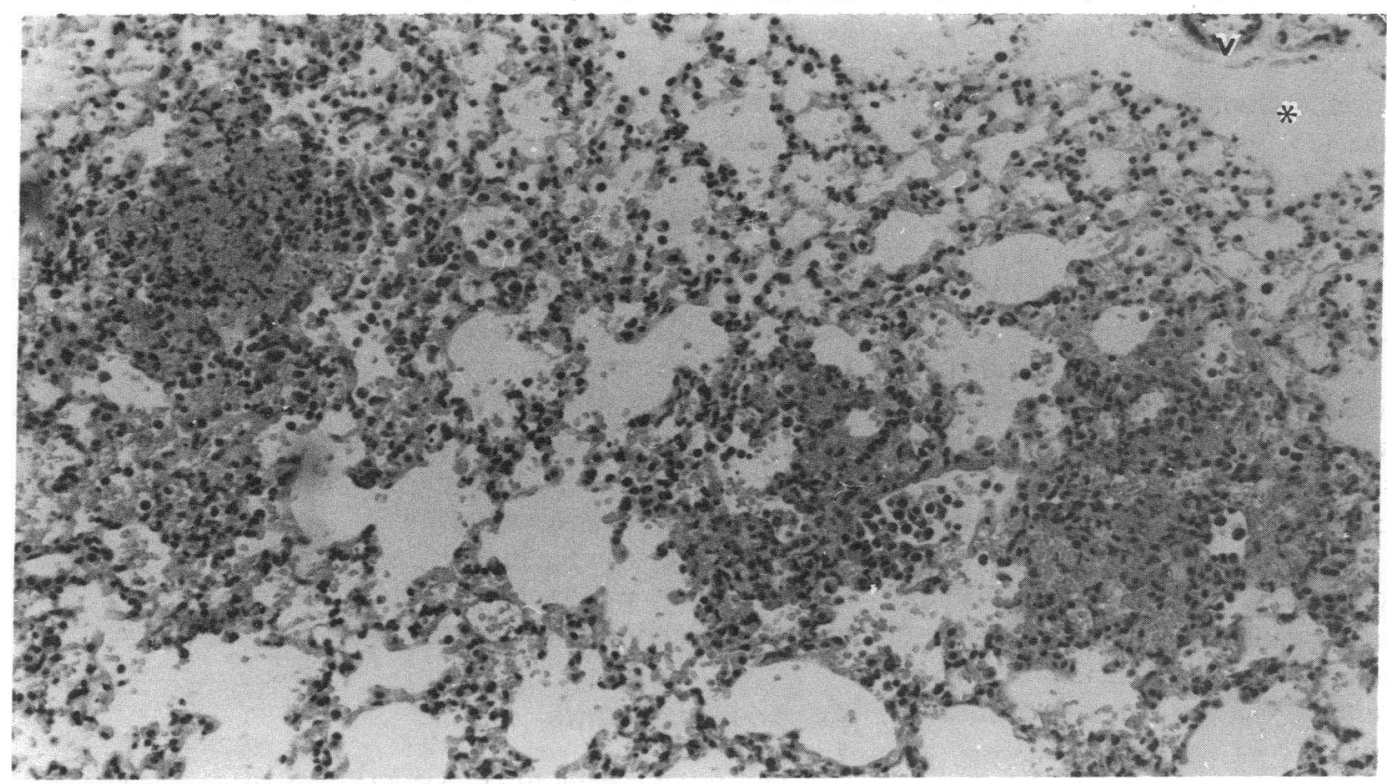

Figure 11. Focal hemorrhagic and exudative lesions in the lung of a mouse of group IIIa. $V$, Part of a vein; asterisk, an area of perivenular edema. Hematoxylin and eosin. $\times 400$. during the immune response, or induced by viruses, may play a critical role in increasing the permeability of the alveolar endothelium. We tested the effects of IL-2 and IFN- $\alpha$ because Puri and Rosenberg have shown that the association of IL-2 and IFN- $\alpha$ induces in mice the most severe vascular leak syndrome in the lung, whereas IFN- $\gamma$ and tumor necrosis factor- $\alpha$ do not exert a similar effect when given alone, nor act synergistically with IL-2 (11). Moreover, the use of IFN- $\alpha$ was motivated by the consideration that epidemic $(26,27)$ or sporadic (28) outbreaks of influenza or other acute infections (2) have been traditionally associated with Goodpasture's hemorrhagic pneumonitis, and IFN- $\alpha$ is induced by viral infection (29).

The combination of IL-2 and IFN- $\alpha$ significantly increased the binding of anti-ABM antibodies to the ABM, as compared with mice injected with anti-ABM antibodies alone, showing that IL-2 and IFN- $\alpha$ are able to expose the ABM, otherwise protected by the unfenestrated alveolar endothelium from circulating IgG. Our results also confirm that IL-2 and IFN- $\alpha$ increased the permeability of the pulmonary vessels more than IL-2 or IFN- $\alpha$ alone (11), indicating that cytokine synergism exerts a critical role in the pathogenesis of passive Goodpasture's hemorrhagic pneumonitis. The decreased binding of anti-ABM antibodies to the GBM of mice injected with IL-2 and IFN- $\alpha$ should probably be ascribed to decreased glomeru-

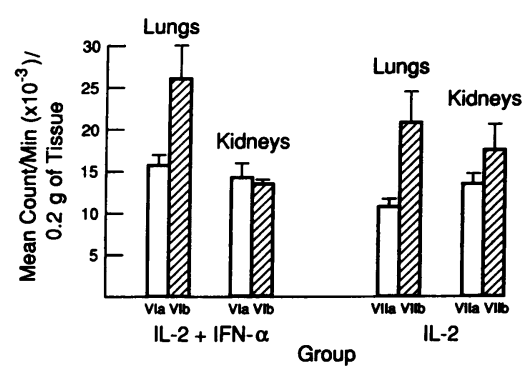

Figure 12. Result of binding of RbABM IgG to the lungs and kidneys of beige C57BL/ $6 \mathrm{~J}-\mathrm{bg}^{\mathrm{J}}$ (open bars) and control C57BL/6J mice (hatched bars) injected with RbABM IgG, IL-2, and IFN- $\alpha$ (groups VIa and VIb) or with RbABM IgG and IL-2 (groups VIIa and VIIb).

In both experiments the binding of RbABM IgG to the lungs in beige mice (groups VIa and VIIa) was inferior to that of control mice (groups VIB and VIIb). lar perfusion because IL-2 (30) and IL-2-activated killer cells (31) induce hemodynamic changes similar to those observed in the early stages of septic shock. These results strengthen the interpretation that the ability of cytokines to expose the ABM to circulating antibodies results from a preferential pulmonary injury. The reasons for this selective injury are not explained by our study. The large surface of the pulmonary endothelium (32) or a local release of cytokines might be contributing factors.

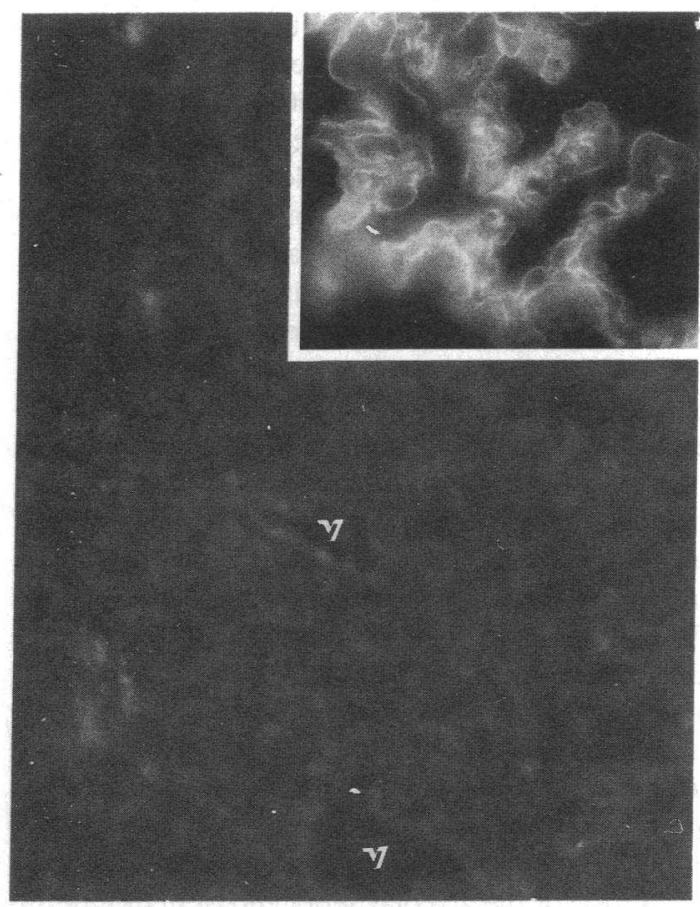

Figure 13. IF micrograph showing absence of deposits of rabbit IgG in the lung of a beige C57BL/6J-bg mouse injected with IL-2, IFN- $\alpha$, and RbABM IgG (group VIa). $\nu$, Veins. Inset, Linear deposits of $\mathrm{Rb}$ IgG in the ABM of a similarly treated control C57BL/6J mouse (group VIb). $\times 300$; inset $\times 500$. 
The role of activated lymphocytes in the pathogenesis of the vascular leak syndrome was studied in vitro and in vivo. Lymphocytes are necessary in vivo since IL-2 is less effective in mice pretreated with irradiation, cyclophosphamide, or cortisone acetate, and in nude mice $(33,34)$. Moreover, treatment of mice with asialo-GM-1 antibodies prevents the vascular leak syndrome induced by cytokines, suggesting that the toxic effect of IL-2 may be mediated by NK cells or activated lymphocytes (35). The results of our study in the NK-deficient beige mice and the observation by electron microscopy of extensive interaction between activated lymphocytes and the pulmonary endothelium are concordant with this interpretation. IL-2 promotes strong adhesion of NK cells to endothelial cells and lysis of these cells $(36,37)$. Moreover, IL-2 induces endothelial expression of polymorphonuclear leukocyte adhesion molecules (ELAM-1) $(38,39)$, procoagulant molecules (40), and intercellular adhesion molecules (ICAM-1), which serve to bind lymphocytes and possibly monocytes (41). When injected in man $(42,43)$ or in mice $(11,33,34)$ IL-2 provokes a vascular leak syndrome resulting from activation of endothelial $(44)$ and NK $(33,34)$ cells.

Distinctive effects, or effects synergistic to those of IL-2, are brought about by IFNs. All three types of IFNs rapidly augment NK cell cytotoxicity by increasing the number of NK cells binding to targets, accelerating the kinetics of lysis, and increasing the recycling ability of active NK cells (45). Combining IL- 2 with IFN- $\alpha$ results in greater than additive augmentation of NK cell activity (46). The multiple effects of the IFNs, in part synergistic to those of IL-2, may explain why mice simultaneously injected with IL- 2 and IFN- $\alpha$ developed the most severe forms of lung vascular leak syndrome.

When mice primed with IL- 2 and IFN- $\alpha$ received anti$\mathrm{ABM}$ antibodies the most striking differences observed in their lungs, as compared with mice injected only with cytokines, were binding of anti-ABM antibodies to the $\mathrm{ABM}$, concomitant fixation of $\mathrm{C} 3$, deposition of fibrinogen, and hemorrhagic and exudative lesions. These changes were prominent at the level of small veins and perivenous alveolar capillaries, the same sites of cytokine-induced vascular leak syndrome. This concordance strengthens the interpretation that the alteration of the blood-alveolar barrier is a critical factor in the development of passive Goodpasture's hemorrhagic pneumonitis. At these discrete sites fixation of complement, chemotactic attraction of inflammatory cells, and activation of coagulation factors amplify the injury. Our study provides only a partial explanation of the mechanisms leading to massive erythrocyte extravasation in or near small veins. It is conceivable that this phenomenon results from structural damage (47); it is also possible that cytokines generate a chemotactic gradient analogous to that stimulating transmigration of neutrophils (48). Absence of proliferative and marked exudative lesions in glomeruli reveals the ability of IL- 2 and IFN- $\alpha$ to transform the lung from a protected organ into a preferential target of antibody-mediated injury.

Lack of lethal pulmonary exudative and proliferative lesions comparable to those presumably occurring in the rare forms of lethal human Goodpasture's hemorrhagic pneumonitis, lack of fibrosis of the alveolar septa and of hemosiderinladen macrophages characteristic of chronic Goodpasture's pneumonitis is explained by the short exposure of murine lungs to anti-ABM antibodies $(48 \mathrm{~h})$ and by the notion that accessibility to ABM antigens is only one of the pathogenetic components in this disease. Development of severe and persis- tent inflammatory changes requires antibody reactivity with the $\alpha 3$ (IV) chain of collagen IV (49), and this reactivity was not established in our study. Moreover, heterologous antibasement membrane antibodies have much broader basement membrane reactivity than does the human counterpart (1). Finally, severe, persistent inflammation seems to require the engagement of cell-mediated hypersensitivity (50).

In conclusion, the results of the experiments show that the selective increased permeability of the alveolar capillary walls, induced by IL- 2 and IFN- $\alpha$, results from severe structural damage of the pulmonary endothelium. Endothelial injury appears a prerequisite for the fixation of antibodies to the ABM and for the development of widespread hemorrhagic and inflammatory lesions. The data are consistent with the hypothesis that cytokines, especially IL- 2 and IFN- $\alpha$, released in the circulation or in the lungs by activated lymphoid cells and cells infected by viruses, have a critical role in the pathogenesis of human Goodpasture's hemorrhagic pneumonitis.

\section{Acknowledgments}

The authors are grateful to Dr. Sandra Kreuscher for her generous help, to Dr. Bice Perussia for useful discussion, and to Mrs. Marilyn Fitzsimmons for typing the manuscript.

This work was supported by grants DK-36807 and DK-35677 from the National Institute of Diabetes and Digestive and Kidney Diseases, National Institutes of Health, Bethesda, MD. Dr. Queluz was supported by fellowship 203225/87 of the CNPq, Brazil.

\section{References}

1. Wilson, C. B., and F. J. Dixon. 1986. The renal response to immunological injury. In The Kidney. B. Brenner and F. C. Rector, Jr., editors. W. B. Saunders Company, Philadelphia. 800-889.

2. Rees, A. J., C. M. Lockwood, and D. K. Peters. 1977. Enhanced allergic tissue injury in Goodpasture's syndrome by intercurrent bacterial infection. Br. Med. J. 2:723-736.

3. Ewan, P. W., and A. J. Rees. 1977. Pulmonary hemorrhage in Goodpasture's syndrome. N. Engl. J. Med. 296:574. (Lett.)

4. Steblay, R. W., and U. H. Rudofsky. 1983. Experimental autoimmune antiglomerular basement membrane antibody-induced glomerulonephritis. I. The effects of injecting sheep with human, homologous or autologous lung basement membranes and complete Freund's adjuvant. Clin. Immunol. Immunopathol. 27:65-80.

5. Lerner, R. A., and F. J. Dixon. 1966. Transfer of ovine experimental allergic glomerulonephritis (EAG) with serum. J. Exp. Med. 124:431-442.

6. Lerner, R. A., R. J. Glassock, and F. J. Dixon. 1967. The role of anti-glomerular basement membrane antibody in the pathogenesis of human glomerulonephritis. J. Exp. Med. 126:989-1004.

7. Jennings, L., O. A. Roholt, D. Pressman, M. Blau, G. A. Andres, and J. R. Brentjens. 1981. Experimental anti-alveolar basement membrane antibody-mediated pneumonitis. I. The role of increased of permeability of the alveolar capillary wall induced by oxigen. J. Immunol. 127:129-134.

8. Downie, G. H., O. A. Roholt, L. Jennings, M. Blau, J. R. Brentjens, and G. A. Andres. 1982. Experimental anti-alveolar basement membrane antibody-mediated pneumonitis. II. Role of endothelial damage and repair, induction of autologous phase, and kinetics of antibody deposition in Lewis rats. J. Immunol. 129:2647-2652.

9. Yamamoto, T., and C. B. Wilson. 1987. Binding of anti-basement membrane antibody to alveolar basement membrane after intratracheal gasoline instillation in rabbits. Am. J. Pathol. 126:497-505.

10. Avasthi, P. S., P. A. Avasthi, S. Tokuda, R. E. Anderson, and R. C. Williams. 1971. Experimental glomerulonephritis in the mouse. I. The model. Clin. Exp. Immunol. 9:667-676.

11. Puri, R. K., and S. A. Rosenberg. 1989. Combined effects of 
interferon-alpha and interleukin-2 on the induction of a vascular leak syndrome in mice. Cancer Immunol. Immunother. 28:267-274.

12. Roder, J. C. 1979. The beige mutation in the mouse. I. A stem cell predetermined impairment in natural killer cell function. J. Immunol. 123:2168-2173.

13. Roder, J. C., M.-L. Lohmann-Matthes, W. Domzig, and H. Wigzell. 1979. The beige mutation in the mouse. II. Selectivity of the natural killer (NK) cell defect. J. Immunol. 123:2174-2181.

14. Saxena, R. K., Q. B. Saxena, and W. H. Adler. 1982. Defective T-cell response in beige mutant mice. Nature (Lond.). 295:240-241.

15. Meezan, E., J. T. Hjulle, and K. Brendel. 1975. A simple, versatile, non-disruptive method for the isolation of morphologically and chemically pure basement membranes from several tissues. Life Sci. 17:1721-1732.

16. Rosenberg, S. A., E. A. Grimm, M. McGrogan, M. Doyle, E. Kawasaky, K. Koths, and D. F. Mark. 1984. Biological activity of recombinant human interleukin-2 produced in Escherichia coli. Science (Wash. DC). 223:1412-1415.

17. Rehberg, E., B. Kelder, E. G. Hoal, and S. Pestka. 1982. Specific molecular activities of recombinant and hybrid leukocyte interferon subtypes. J. Biol. Chem. 257:11497-11502.

18. Brunda, M. J., and D. Rosenbaum. 1984. Modulation of murine natural killer cell activity "in vitro" and "in vivo" by recombinant human interferons. Cancer Res. 44:597-601.

19. Andres, G. A., L. Accini, S. M. Beiser, C. L. Christian, G. A. Cinotti, B. F. Erlanger, K. C. Hsu, and B. C. Seegal. 1970. Localization of fluorescein labeled antinucleoside antibodies in glomeruli of patients with active systemic lupus erithematosus nephritis. J. Clin. Invest. 49:2106-2118.

20. Pirani, C. L., V. E. Pollak, and F. D. Schwartz. 1964. The reproducibility of semiquantitative analyses of renal histology. Nephron. 1:230-237.

21. Karnowsky, M. J. 1965. A formaldehyde-glutaraldehyde fixative of high osmolality for use in electron microscopy. J. Cell Biol. 27:137A-138A.

22. McConahey, P. J., and F. J. Dixon. 1966. A method of trace iodination of proteins for immunological studies. Int. Arch. Allergy Appl. Immunol. 29:185-189.

23. Pressman, D., E. D. Day, and M. Blau. 1957. The use of paired labeling in the determination of tumor localizing antibodies. Cancer Res. 17:845-850.

24. Wilson, C. B., and F. J. Dixon. 1970. Antigen quantitation in experimental immune complex glomerulonephritis. I. Acute serum sickness. J. Immunol. 105:279-290.

25. Siegel, S. 1956. Nonparametric Statistics. McGraw-Hill Inc., New York. 312 pp.

26. Perez, G. O., S. Bjornsson, A. H. Ross, J. Amato, and N. Rothfield. 1974. A mini-epidemic of Goodpasture's syndrome: clinical and immunological studies. Nephron. 13:161-173.

27. Wilson, C. B., and F. J. Dixon. 1973. Anti-glomerular basement membrane antibody-induced glomerulonephritis. Kidney Int. 3:74-89.

28. Wilson, C. B., and R. C. Smith. 1972. Goodpasture's syndrome associated with influenza $\mathrm{A}_{2}$ virus infection. Ann. Intern. Med. 76:9194.

29. Toy, J. L. 1983. The interferons. Clin. Exp. Immunol. 54:1-13. 30. Oguibene, F. P., S. A. Rosenberg, M. Lotze, J. Skibber, M. M. Parker, J. H. Shelhamer, and J. E. Parillo. 1988. Interleukin-2 administration causes reversible hemodynamic changes and left ventricular dysfunction similar to those seen in septic shock. Chest. 94:750-754.

31. Gaynor, E. R., L. Vitek, L. Sticklin, S. P. Creekmore, M. E. Ferrara, J. X. Thomas, Jr., S. G. Fisher, and R. I. Ficher. 1988. The hemodinamic effects of treatment with interleukin-2 and lymphokine-activated killer cells. Ann. Intern. Med. 109:953-958.

32. Guyton, A. C. 1976. Textbook of Medical Physiology. 5th ed. W. B. Saunders Company, Philadelphia. 537-539.

33. Rosenstein, M., S. E. Ettinghansen, and S. A. Rosenberg. 1986. Extravasation of intravascular fluid mediated by the systemic administration of recombinant interleukin-2. J. Immunol. 137:1735-1742.
34. Ettinghansen, S. E., R. K. Puri, and S. A. Rosenberg. 1988. Increased vascular permeability in organs mediated by the systemic administration of lymphokine-activated killer cells and recombinant interleukin-2 in mice. J. Natl. Cancer Inst. 80:177-188.

35. Gately, M. K., T. D. Anderson, and T. J. Hays. 1988. Role of asialo-GM1-positive lymphoid cells in mediating the toxic effects of recombinant IL-2 in mice. J. Immunol. 141:189-200.

36. Aronson, F. R., P. Libby, E. P. Brandon, M. W. Janicke, and J. W. Mier. 1988. IL-2 rapidly induces natural killer cell adhesion to human endothelial cells: a potential mechanism for endothelial injury. J. Immunol. 141:158-163.

37. Damle, N. K., L. V. Doyle, J. R. Bender, and E. C. Bradly. 1987. Interleukin-2-activated human lymphocytes exhibit enhanced adhesion to normal vascular endothelial cells and cause their lysis. $J$. Immunol. 138:1779-1785.

38. Pober, J. S., M. P. Bevilacqua, D. L. Mendrick, L. A. Lapierre, W. Fiers, and M. A. Gimbrone, Jr. 1986. Two distinct monokines, interleukin-1 and tumor necrosis factor, each independently induce biosynthesis and transient expression of the same antigen on the surface of cultured human vascular endothelial cells. J. Immunol. 136:1680-1687.

39. Bevilacqua, M. P., J. S. Pober, D. L. Mendrick, R. S. Cotran, and M. A. Gimbrone, Jr. 1987. Identification of an inducible endothelial-leukocyte adhesion molecule ELAM-1. Proc. Natl. Acad. Sci. USA. 84:9238-9242.

40. Bevilacqua, M. P., J. S. Pober, G. R. Majeau, R. S. Cotran, and M. A. Gimbrone, Jr. 1984. Interleukin-1 (IL-1) induces biosynthesis and cell surface expression of procoagulant activity in human vascular endothelial cells. J. Exp. Med. 160:618-623.

41. Marlin, S. D., and T. A. Springer. 1987. Purified intercellular adhesion molecule-1 (ICAM-1) is a ligand for lymphocyte functionassociated antigen-1 (LFA-1). Cell. 51:813-819.

42. Rosenberg, S. A., M. T. Lotze, L. M. Muul, A. V. Chang, F. P. Avis, S. Leitman, M. Lidehan, C. N. Robertson, R. E. Lee, J. T. Rubin, C. A. Seipp, C. G. Simpson, and D. E. White. 1987. A progress report on the treatment of 157 patients with advanced cancer using lymphokine-activated killer cells and interleukin-2 or high dose interleukin-2 alone. N. Engl. J. Med. 316:889-897.

43. Rosenberg, S. A., J. J. Mule, P. J. Speiss, C. M. Reichert, and S. Schwarz. 1985. Regression of established pulmonary metastases and subcutaneous tumor mediated by systemic administration of highdose recombinant IL-2. J. Exp. Med. 161:1169-1188.

44. Cotran, R. S., J. S. Pober, M. A. Gimbrone, Jr., T. A. Springer, E. A. Wiebke, A. A. Gaspari, S. A. Rosenberg, and M. R. Lotze. 1987. Endothelial cell activation during interleukin-2 immunotherapy: a possible mechanism for the vascular leak syndrome. J. Immunol. 139:1883-1888.

45. Trinchieri, G., and B. Perussia. 1984. Biology of disease. Human natural killer cells: biologic and pathologic aspects. Lab. In vest. 50:489-513.

46. Brunda, M. J., D. Tarnowski, and V. Davatelis. 1986. Interaction of recombinant interferons with recombinant interleukin-2: differential effects on natural killer cell activity and interleukin-2 activated killer cells. Int. J. Cancer. 37:787-793.

47. Cybulsky, M. I., I. G. Colditz, and H. Z. Movat. 1986. The role of interleukin-1 in neutrophil leukocyte emigration induced by endotoxin. Am. J. Pathol. 124:367-372.

48. Moser, R., B. Schleiffenbaum, P. Groscurt, and J. Fehr. 1989. Interleukin- 1 and tumor necrosis factor stimulate human vascular endothelial cells to promote transendothelial neutrophil passage. J. Clin. Invest. 83:444-455.

49. Hudson, B. G., J. Wieslander, B. J. Wisdom, and M. E. Noelken. 1989. Biology of Disease. Goodpasture's syndrome: molecular architecture and function of the basement membrane antigen. Lab. Invest. 61:256-269.

50. Clayman, M. D., L. Michaud, and E. G. Neilson. 1987. Murine interstitial nephritis. VI. Characterization of the B cell response in anti-tubular basement membrane disease. J. Immunol. 139:22422249. 